\title{
Circular Concrete-Filled Tubular Columns: State of the Art Oriented to the Vulnerability Assessment
}

\author{
Rolando Chacón*
}

Departmento de Ingenieria de la Construccion, Calle Jordi Girona 1-3. Campus Nord UPC. Edificio C1-207. 08034. Barcelona, Spain

\begin{abstract}
The vulnerability of framed structures has been analyzed until recently from two different perspectives: Structural and socio-economical. For the sake of assessing the former, indexes and objective measurements have been proposed in the literature. These indexes include relatively accurate assessments of the strength, ductility, energy absorption, fire, blast response and resilience of the elements in order to define a higher-level structural magnitude. Similar approaches are performed with the latter when it comes to assessing damage, economical aspects, social and other important factors.

On the other hand, concrete-filled tubes (CFT) have proven structurally efficient due to their relatively high strength-toweight ratio. Considerably complete state-of-the-art reviews are available for these members when it comes to analyzing their strength and overall or local buckling in static and/or dynamic responses. Reviews concerning important issues related to the structural vulnerability of those members are, however, scarce.

In this paper, a state-of-the art dealing with the behavior of concrete-filled tubes is presented. The novelty of such approach is to present research concerning CFT but, in this case, from a structural vulnerability perspective (not socioeconomical), that is to say, summarizing references concerning seismic response, fire resistance, impact response and other main characteristics that are further used when defining the aforementioned indexes. Relevant numerical, experimental and theoretical studies presented in recent years are pinpointed as well as potential research trends.
\end{abstract}

Keywords: CFT, composite structures, earthquake resistance, fire resistance, impact resistance, vulnerability assessment.

\section{INTRODUCTION}

The vulnerability of a system to any thread is a matter of a major concern in humankind. Disasters, accidents, climate change or financial crisis are only four of the numerous threads that natural or artificial systems may undergo during a lifetime. In the particular field of structural engineering, the vulnerability of framed structures is defined as the likelihood of encountering a severe global damage of the structure (building, bridge, dam, platform, etc.) when one or several of its members are threatened by a particular accidental situation. A structure is vulnerable if a relatively small damage (in a single part or the whole structure) leads to disproportionately large consequences. The vulnerability of a framed structure may be measured in terms of its physical response towards those threats and in terms of its associated socioeconomic damage. For both cases, authors have proposed objective quantities for measuring the vulnerability of the structure as a function of several parameters related to the structural members, ground, architectural design, maintenance of the structure and natural environment. Currently available vulnerability indexes encompass several of the aforementioned characteristics in a single value. When it comes to the parameters associated with the structural members, the

*Address correspondence to this author at the Departmento de Ingenieria de la Construccion, Calle Jordi Girona 1-3. Campus Nord UPC. Edificio C1207. 08034. Barcelona, Spain; Tel: 0034934017349;

E-mail: rolando.chacon@upc.edu vulnerability indexes are generally obtained by weighing several of their structural characteristics such as ductility, strength, fire resistance, energy absorption, impact and blast resistance or others.

On the other hand, concrete-filled tubes (CFT) are widely used as columns in civil engineering. CFT consist of a steel tube with a concrete core casted inside. Several applications of CFT (ranging from medium-to-tall buildings to bridge construction) are available. Both circular and square CFT are available in construction, being the former more resistant, ductile and well understood but being the latter more popular for framed structures due to ease of connections. CFT have become popular in structural applications due to their earthquake-resistant properties and the relatively high strength-toweight ratio. The static behavior of CFT has been analyzed and thousands of tests on CFT subjected to axial and flexural loads have been gathered by researchers in the U.K [1] and are nowadays available and continuously updated by researchers from the University of Bradford under the supervision of Prof. D. Lam [2]. The vast majority of studies have pointed out key beneficial aspects of CFT when subjected to different types of loading. Their cross-sectional resistance is systematically compared to the resistance of a pure steel or pure concrete element. Consensus concerning this matter has been achieved among researchers: the resistance of CFT is quite higher than the addition of the resistances of each material when considered separately. Relatively complete stateof-the-art reports concerning the cross-sectional resistance of 


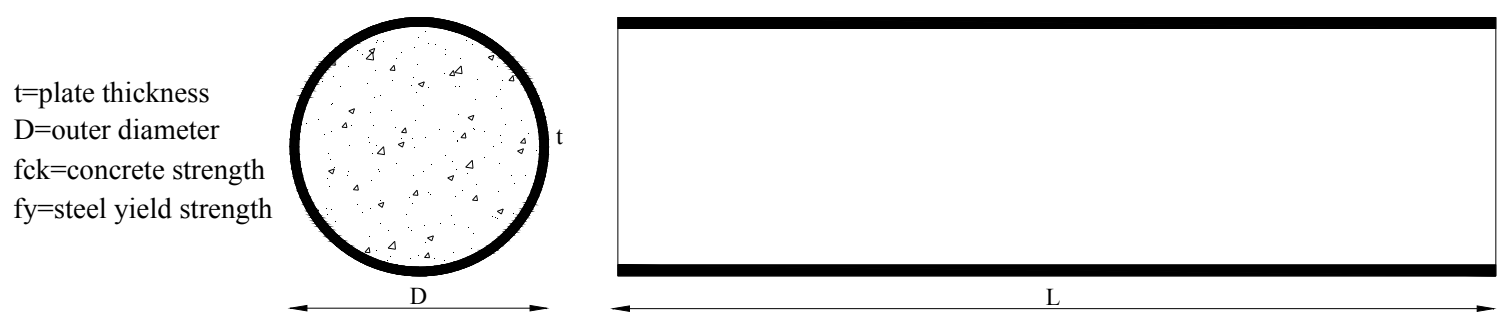

Fig. (1). Views of concrete-filled tubes. geometry and material properties.

CFT to static and dynamic loads are available $[3,4]$. These reports discuss topics ranging from the nonlinear behavior, composite action, bond effects, hysteresis response and overall/local buckling of columns with different length-todiameter and diameter-to-wall thickness ratios. The NSEL report [4] includes an exhaustive review of analytical and experimental studies concerning the cross-sectional and overall buckling resistance of CFT as well as the seismic response focused on connections. In addition, reviews concerning the numerical modeling of CFT have also been published [5]. This review presents a particular emphasis in the potential use of relatively simplified beam models (fiberbased or lumped-plasticity based) or alternatively, fully nonlinear 3D models which encompass confinement, bond effect, local/global buckling and other expected failure phenomena.

In recent years, an increasing amount of papers and research works concerning CFT has been published. These research works include vast numerical studies with emphasis in relatively new aspects over CFT such as fire resistance, blast or impact loading, ductility or other aspects related to new materials or geometries. As stated previously, those aspects are fundamental when it comes to defining objective measurements concerning the vulnerability of framed structures.

In this review, a state-of-the-art report concerning the structural characteristics of CFT associated with vulnerability is presented. The novelty of this research work is to provide newly available data and references related to the structural response of CFT but also, to organize these references from a vulnerability point of view, emphasizing in three separate aspects: seismic response, fire resistance and impact loading.

The paper is organized in sections in which reviews concerning the aforementioned topics are presented separately. In addition, sections concerning the most studied topics such as cross-sectional resistance, overall/local buckling, are added for the sake of completeness and for the sake of updating some references. The studies presented herein are limited to circular steel tubes with concrete casted inside. Other geometries such as square, rectangular or elliptical sections are not covered. Fig. (1) depicts the geometrical characteristics of CFT as well as the nomenclature and geometrical proportions used throughout the paper.

\section{CROSS-SECTIONAL RESISTANCE OVERALL AND LOCAL STABILITY}

In pure compression, the mechanical basis that underpins the cross-sectional resistance of CFT is the passive confine- ment provided by the steel tube to the concrete core. The mechanical behavior of short stub CFT was first described in $[6,7]$. Ever since that, the basic principles have inspired researchers in defining more refined quantitative predictions of the cross-sectional resistance of CFT. Fig. (2) shows schematically this basic mechanical principle. Considering that both materials present a different Poisson coefficient, the lateral expansion of both bodies differ when subjected to stresses along the longitudinal direction.

In the initial stage of a hypothetical monotonically increasing load applied concentrically on a CFT cross-section, the steel tube expands faster in the radial direction than the concrete core, i.e., the steel tube does not provide any restraint to the concrete body. Compressive hoop stresses are formed in the steel tube and lateral tensile stresses in the concrete core (Fig. $2 v_{\mathrm{c}}<v_{\mathrm{s}}$ ). The lateral tension on the concrete generates micro cracking which affects the Poisson coefficient and the overall stiffness of the body. At some point, the lateral expansion of the concrete core catches up the steel tube and the steel tube starts providing a lateral restraint (Fig. $2 v_{\mathrm{c}}>v_{\mathrm{s}}$ ). The hoop stresses in the steel become tensile and from this point onwards, the steel is subjected to biaxial stresses (compressive and tensile) whereas the concrete core is subjected to tri-axial compressive stresses.

As previously stated, CFT provide a greater crosssectional resistance than if the contributions of steel and concrete are calculated separately. This increase in capacity is due to the considerable confinement effect given by the steel tube to the concrete core. The passive confinement the steel tube provides to the concrete core is a key aspect which allows determining the cross-sectional capacity of the CFT. This effect has been studied considerably. Broadly speaking, it can be stated that the cross-sectional resistance $\mathrm{N}_{\mathrm{pl}}$ of a CFT is given as the sum of the partial resistances of the concrete core and the steel tube (eq. (1)). In Eq. (1), $\alpha$ and $\beta$ are coefficients which modify the partial resistances $A_{c} \cdot f_{c k}$ (concrete) and $\mathrm{A}_{\mathrm{s}} \cdot \mathrm{f}_{\mathrm{y}}$ (steel) for simulating the confinement effect accordingly.

$$
N_{p l}=\alpha \cdot A_{c} \cdot f_{c k}+\beta \cdot A_{s} \cdot f_{y}
$$

The passive confinement has been mostly studied in concentrically compressed CFT. Researchers have recently provided different alternatives for obtaining $\alpha$ and $\beta$ as a function of the cross-sectional geometry [8-11], i.e., the diameter $D$, the thickness of the tube $t$, and the nominal strengths of the materials $f_{c k}$ and $f_{y}$. The definition of $\alpha$ and $\beta$ has been traditionally based upon a strong phenomenological insight with additional empirical calibrations of some necessary coefficients. It has been recognized that these coefficients are 

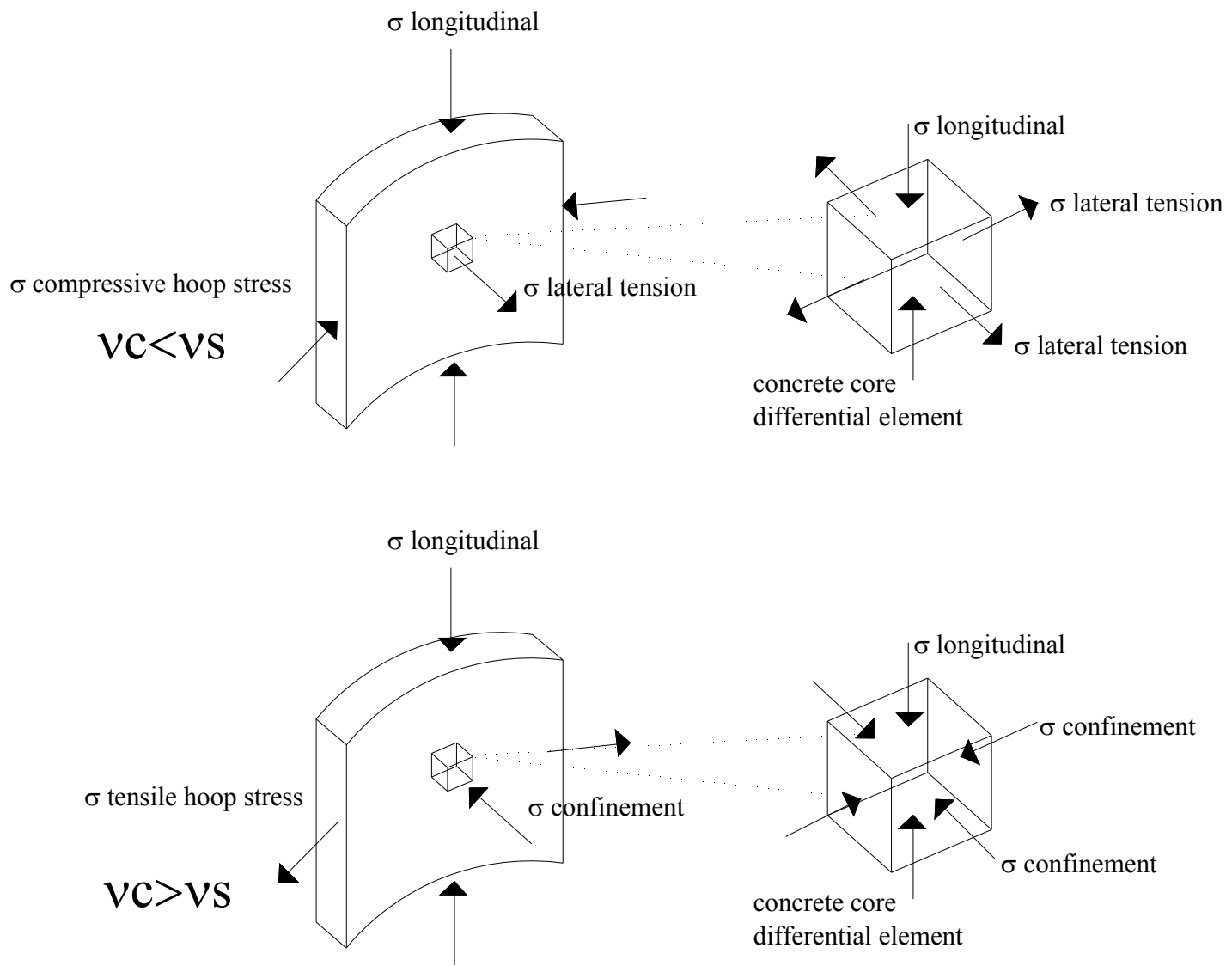

Fig. (2). Mechanical principle for the cross-sectional resistance (compression) [11].

strongly dependent on $\delta$ (eq. 2), which represents the ratio between the partial contribution of the tube to the resistance to the arithmetic sum of the partial resistances of the tube and the core. This parameter is limited in EN1994 [12] for CFT as shown in eq. 2.

$\delta=\frac{A_{s} \cdot f_{y}}{A_{s} \cdot f_{y}+A_{c} \cdot f_{c}^{\prime}} \quad 0,2 \leq \delta \leq 0,9$

More recently, in a previous work performed in [13], it is statistically demonstrated that in short columns (no overall buckling observed) the proportion L/D may also play a role in the definition of $\mathrm{N}_{\mathrm{pl}}$.

These proposals have been statistically and systematically evaluated in recent studies $[14,15]$ by comparing their own experimental results with the corresponding theoretical capacities and those included in structural codes. These authors concluded that the ultimate load capacities predicted by [8-11] lead to satisfactory results. Furthermore, comparisons between these proposals and 344 experimental tests found in $[1,2]$ were performed in [13]. It was concluded that the predictions given in $[10,11]$ provide better agreement with tests among those studied. It is important to pinpoint that in the experimental database used for drawing these conclusions, the $\mathrm{L} / \mathrm{D}$ and $\mathrm{D} / \mathrm{t}$ ratios of the tests were chosen in such a way that no local/overall buckling was expected to occur as the primary failure mode. In a relatively recent work [16], the load-bearing capacity of CFT is studied experimentally, analytically and also from the structural codes perspec- tive. Comparisons between relevant codes and experimental/numerical results are thoroughly performed. Numerical and experimental studies related to this topic are continuously refined with more models, predictions and details of the formulations [16-18]. A comprehensive summary of several design codes and the cross-sectional resistance of CFT is provided in [19].

A considerable amount of other analytical predictions are also available in $[3,4]$. Since this paper is focused mainly on new research concerning CFT and on the phenomena associated with its vulnerability, these expressions are not detailed herein.

In pure bending, simplified rigid plastic approaches for the cross-sectional resistance have been defined (see Fig. 3). The steel tube is able to resist both compression and tension whereas the concrete core provides a compression component (no tension) with an "unconfined" resistance. Investigations dealing with the effect of the geometric proportions, material properties and with proper survey of structural codes are available for such cases [20-23].

Substantial structural demands are generally imposed on column members in mid- to high-rise buildings. High axialbending interaction is expected in CFT that belongs to such structures. For the sake of accounting for such interaction, cross-sectional interaction diagrams allows plotting the interaction diagram. In Fig. (4), point A (pure compression), the resistance provided by codes usually includes a certain level of confinement). This confinement is accounted for 


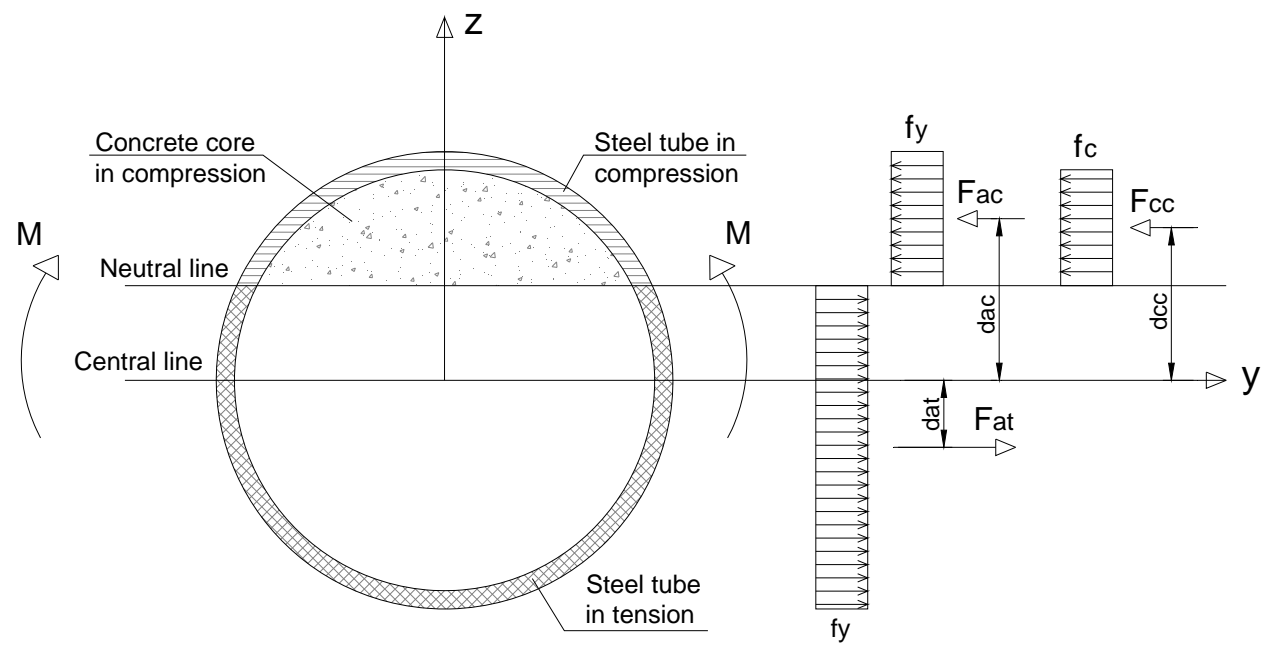

Fig. (3). Mechanical principle for the cross-sectional resistance (bending) [13].

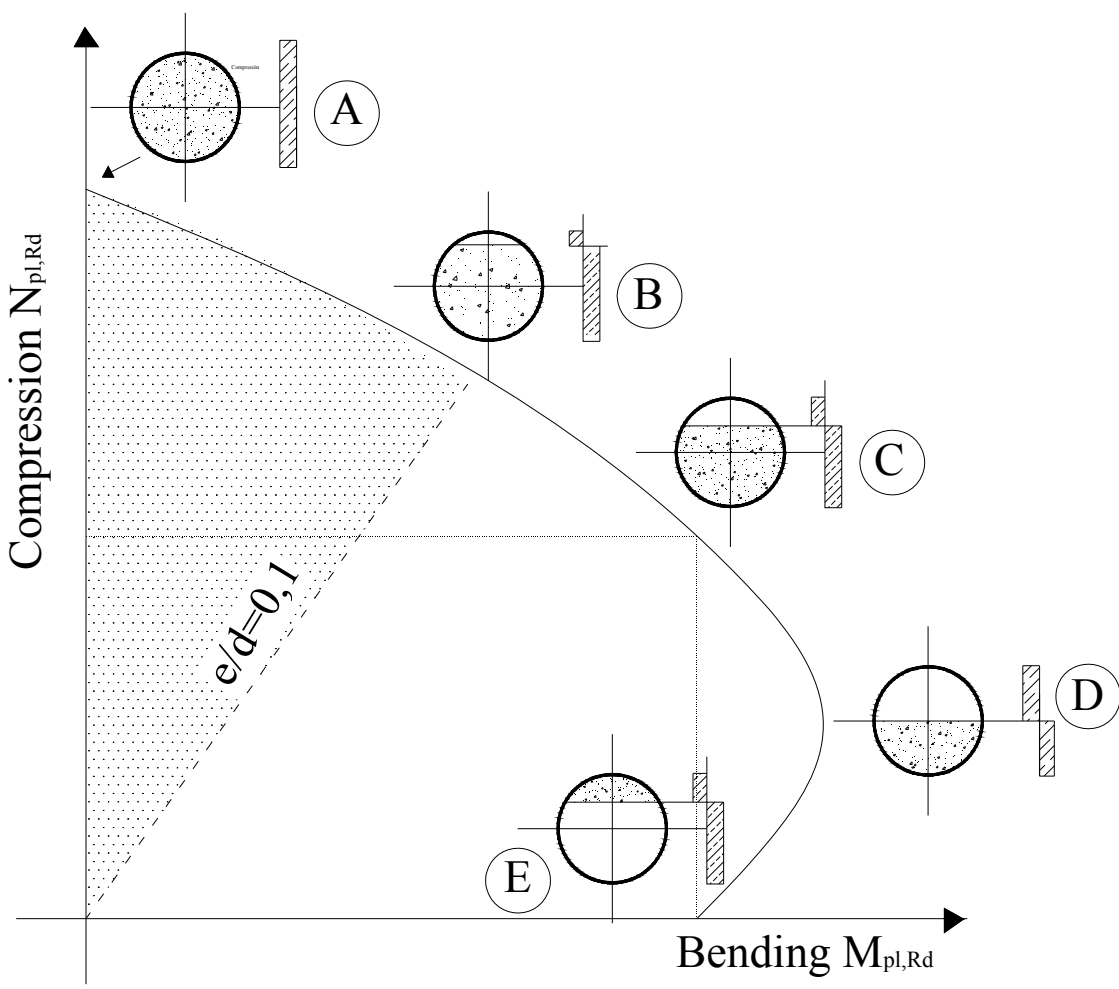

Fig. (4). Cross-sectional interaction diagram for a CFT [13].

when the load eccentricity is rather low. When the load eccentricities are high, the confinement is not taken into account and the cross-sectional resistance is obtained by simply using nominal strengths and geometry oh the CFT via equilibrium equation in a rigid plastic response. Experimental and numerical works dealing with such interactions are also available [24, 25].

On the other hand, overall and local instability of CFT have been studied in last decades. Broadly speaking, the former case depends upon the length-to-diameter L/D ratio whereas the latter, upon diameter-to-thickness ratio $\mathrm{D} / \mathrm{t}$ of the steel tube (the material properties and the load eccentricity also play a considerable role).

The overall buckling of CFT has been studied since the sixties. Based on experimental results, the effect of the slenderness, eccentricity of the load and the type of steel were systematically studied $[26,27]$. The authors pinpointed that for slender columns with high eccentricity ratio, the effect of confinement was negligible whereas for columns with medium slenderness with concentric load, the confinement was higher.

The elastic buckling of composite members has been theoretically approached by defining an equivalent stiffness 
$(\mathrm{E} \cdot \mathrm{I})_{\mathrm{eq}}$ which accounts for the presence of two different materials. The transformation is performed under the assumption that materials remain elastic until instability occurs. Hundreds of publications concerning this topic are available. One of the greatest databases concerning slender CFT is maintained by Prof. Hajjar and co-workers from Northeastern University under the name of "Composite Members Wiki" $[4,28]$. This wiki is accessible to contributors worldwide for additions and changes. Together with the available tests collected in $[1,2]$, the publicly available databases concerning CFT are remarkable.

On the other hand, local buckling in CFT has been studied to a lesser extent. It is understood that CFT columns subjected to bending and/or compressive loads might be prone to local buckling when the $\mathrm{D} / \mathrm{t}$ ratio of the steel tube is high. The critical buckling loads of the plates belonging to CFT may condition the cross-sectional capacity of the members. The critical buckling mode associated with local instability of a steel plate of a CFT might be labeled as "outwards buckling" since the steel plate is not able to develop inwards waves. Few information concerning mathematical developments or eigenvalue analyses of such phenomenon are available in the literature $[29,30]$. The cross-sectional resistance of CFT has been traditionally decoupled from the local buckling phenomenon by limiting the $\mathrm{D} / \mathrm{t}$ ratio of the tube to certain values. Numerical studies performed in [31], pinpoint that the post-buckling strength of CFT is greater than what has traditionally provided in guidelines. Design formulae based upon the direct strength method (DSM) and accounting for this post-buckling reserve were provided in [32]. These formulae do not require the computation of the effective area of the plate and are derived empirically from a series of experimental tests. Major contributions concerning the field of local buckling have been performed in Australia by Prof. Uy and co-workers. This research group also includes works related to square and rectangular CFT as well as to a wide variety of structural materials [33]. Fig. (5) displays numerical simulations of typical failure due to local buckling in purely compressed or subjected to bending members.
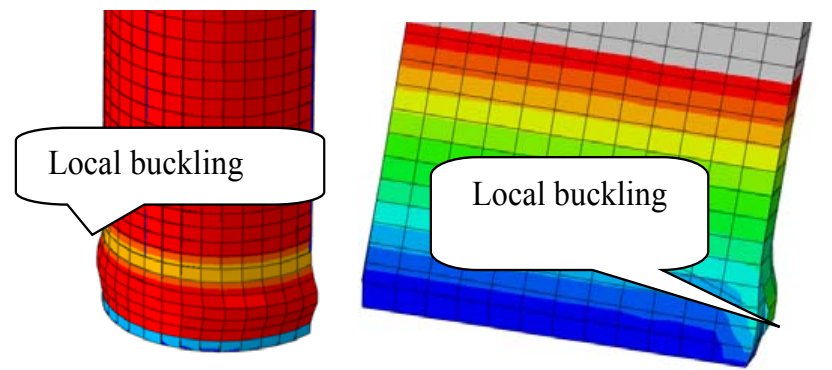

Fig. (5). Local buckling observed in CFT. Pure compression and pure bending [31].

Recent studies concerning strength of stocky and/or slender CFT are focused in the usage of new materials such as non-compact slender CFT stainless steel CFT [34] or elliptical hollow sections [35]

\section{SEISMIC RESPONSE}

The seismic response of CFT has been widely studied for square/rectangular cross-sections [36-38]. Frames are easier to assemble with square/rectangular sections than with circular CFT but conversely these members provide increased local buckling, reduced confinement and lesser ductility. Circular CFT sections need complex arrangements over the beam-to-column connections (Fig. 6).

The main aspects that have been investigated in the seismic response of CFT circular are related to:

- Seismic behavior of beam-to-column connections.

- Local buckling, tensile fracture and cracking under cyclic loading.

The first of the aforementioned points has been widely studied for different structural types. A wide range of beamCFT column connections have been studied over the past several decades. An example of a bolted connection for CFT in seismic areas is described in [39]. A convenient connection involves an attachment of the steel beam to the skin of the steel tube for simple connections. Researchers, however, have pointed out that welding the beam to the steel tube (directly) should not be used in typical moment-resisting frames. The tube walls may undergo severe distortions and thus, the formation of plastic hinges is questionable. One recent publication describing experimentally the behavior of several connections presents up-to-date references concerning this topic [40]. In addition, the database provided in [28] also includes a continuously updating collection of references and tests for different geometries and materials. Research related to seismic resistance of beam-to-columns connections in CFT has been primarily analytic-experimental $[41,42]$. Numerical studies dealing with this topic are also abundant [43, 44]. In addition, circular CFT may also be used as diagonal braces due to their excellence performance in energy absorption. In this case, in principle, the loss of such members is at some point desirable. Recent experimental research shows the seismic behavior of such components [45] which are displayed schematically in Fig. (7).

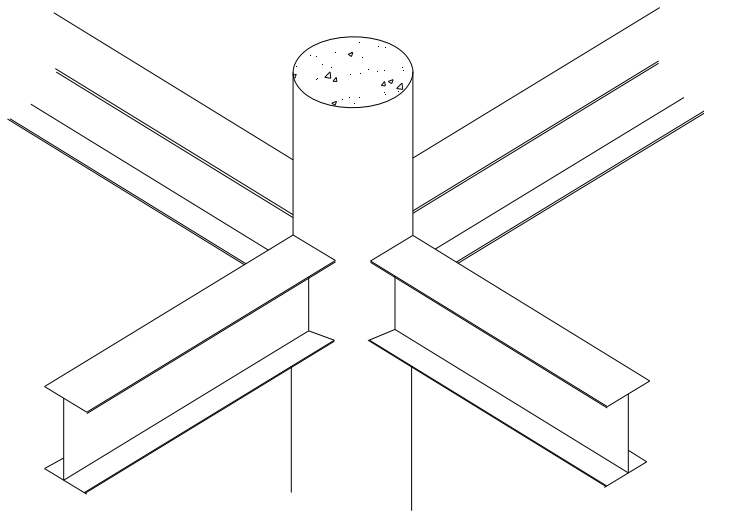

Fig. (6). CFT beam-to-column directly welded connection [44].

The second point has been widely studied in Japan by Prof. Goto and co-workers and considerably dealt with in world congresses related to earthquake engineering. [46-49]. The behavior of CFT, especially the damage propagation associated with accumulated plastic strain due to local buckling and tensile strains is largely described analytically and experimentally. These studies include subjecting framed structures assembled with CFT (via numerical models) to reported ground motions such as El-Centro, Taft, Kobe and 


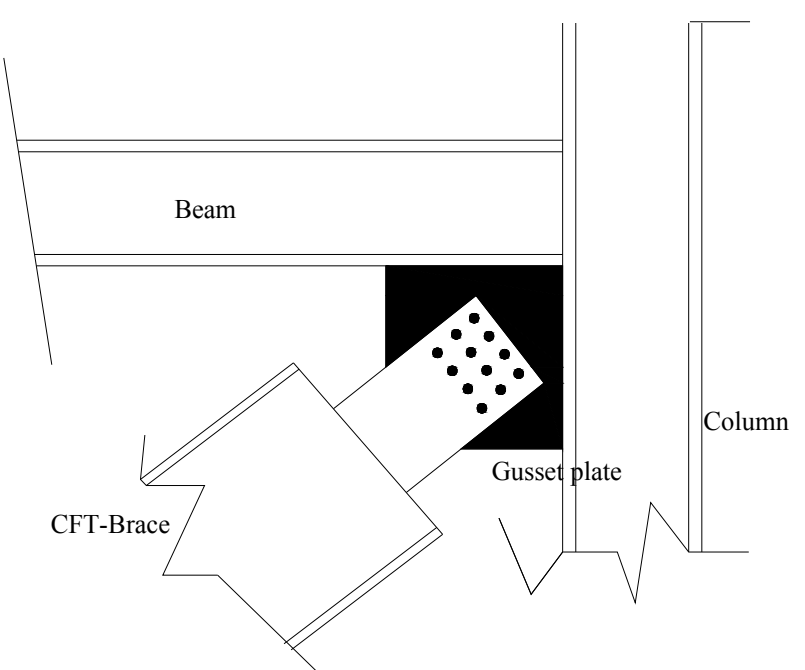

Fig. (7). CFT-brace. Main components in a beam-to-column connection.

others. One interesting proposal found in [47] is the formulation of the accumulated damage as a decoupled function of the accumulated plastic strain due to tensile stresses added to the plastic stresses due to local buckling when the loads are reversed. The formulation includes several explicit expressions. Fig. (8) displays details of the experimental tests (damage due to cracking and local buckling) of CFT under cyclic loading. More recently, numerical models dealing with the hysteretic behavior of CFT with large sections have been provided [49], in which the material modeling (concrete) is based upon damage plasticity with additional implementation of a crack opening formulation. Finally, though not directly related to seismic response, research works related to ductility demand on circular CFT subjected to lateral displacement and axial loading is available [50].

\section{FIRE RESISTANCE}

Fire is one of the potential threats that structures assembled with CFT columns may undergo. The fire resistance of the structural elements is a major verification that must be performed during the design process of a building. In the particular case of columns, the members are generally slender and subjected to a combination of axial and bending loads. Thus, these elements are prone to overall buckling. Depending on several factors related to the future use and characteristics of the building to be designed, the required fire resistance time (the main parameter) ranges from 30 to 180 minutes. This time accounts for all combustible contents within the building including furnishings, equipment, as well as combustible construction components. Tipically, most of the fire load in building results from contents are introduced once the construction is completed.

The resistance of CFT to fire has been tackled by researchers from a wide range of approaches i.e., analytical, empirical, experimental and numerical. The basis underpinning the resistance of CFT subjected to fire is a coupled thermo-mechanic phenomenon between two separated bodies with different thermo-mechanic characteristics. Account must be taken for a nonlinear contact between the steel tube and the concrete core that may potentially undergo different phenomena such as cracking, yielding, overall/local buckling with a heavy component of heat transfer and conductivity. The evolution of the strength of the different components of a CFT column is decreasingly abrupt with time (Fig. 9).

Research concerning the fire resistance of CFT gained popularity in the beginning of the eighties with experimental tests at CIDECT [51, 52], in Japan [53, 54] and in Canada $[55,56]$. Ever since that, researchers in Canada and Japan have proposed theoretical formulae and design methods aimed at predicting the reduced capacity of CFT as a function of the fire loading (and thus, the time associated with the design fire) and naturally, the CFT itself [57-59].

Nowadays, the structural North American standards are based on the approaches performed by Kodur and his coworkers [60-62]. This approach consists of a single design equation which includes the main parameters affecting the phenomenon.

In China, Han and his co-workers [63-67] have contributed enormously to the development of rules, theoretical formulae and design expressions concerning unprotected CFT subjected to fire loading under axial-bending loads. The Chinese design rules establish an equation to calculate the thickness of the required external fire protection for achieving a certain level of fire loading (i.e., duration of the fire).

In Europe, the fire resistance of CFT columns has been studied by several research groups theoretically, experimentally and numerically. Three methods are available in European Standards [68]: i) design based upon tabulated data ii) simplified calculations, iii) advances and sophisticated methods.
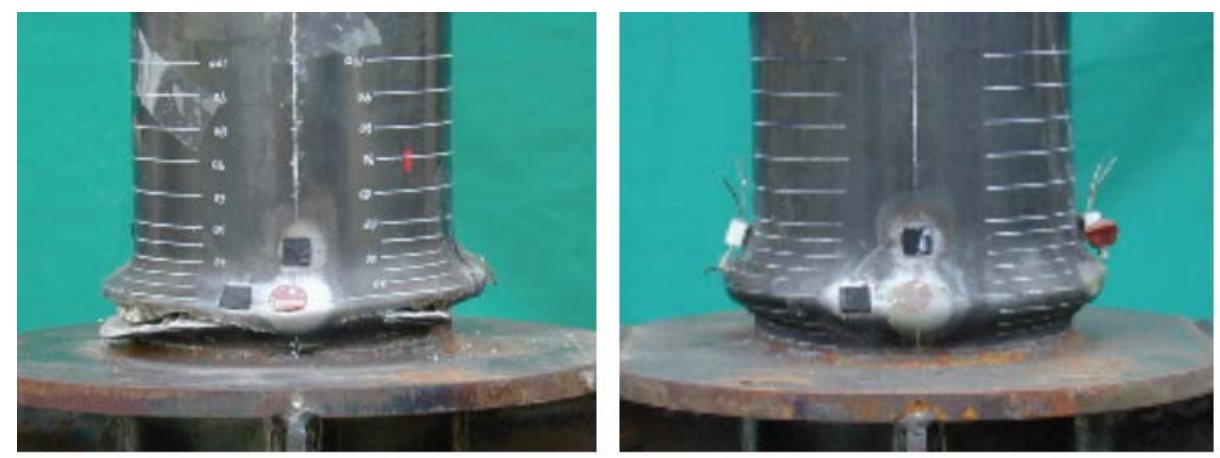

Fig. (8). Cracking (left) and local buckling (right) in CFT due to cyclic loading [48]. 
i) The first approach is limited to a small number of cases and provides minimum cross-sectional dimensions that a CFT must have for the sake of achieving a standardized level of performance. Authors such as Rush [69] in his reviews of the methods for the calculating the fire resistance of CFT pinpoints the potential level of unsafety the usage of such tables may lead to.

ii) Clearly depicted in [70] by Espinós et al., the second approach has been widely studied by researchers such as Wang and his co-workers [71-73] as well as many researchers in Europe. [74-76]. The method consists of applying reduction coefficient to the mechanical properties of the concrete and steel assembling the CFT as a function of the fire loading and thus, using similar verifications as for the case of the resistance of the members (cross-sectional and buckling verifications).

iii) Advanced calculations are based upon the usage of finite-elements models that include a proper coupling between the thermal and mechanical phenomenon of CFT subjected to fire. The level of accuracy of the predictions of such models is uncontested. This type of modeling has traditionally been limited to researchers $[77,78]$. However, due to the increasing computing capacity and versatility of the available user-friendly Software.

Research dealing with CFT, new materials and new structural types is continuously updated [79-82]. Newly available user-friendly numerical models able to couple such intrincate phenomena are powerful tools for refining the hitherto performed studies.

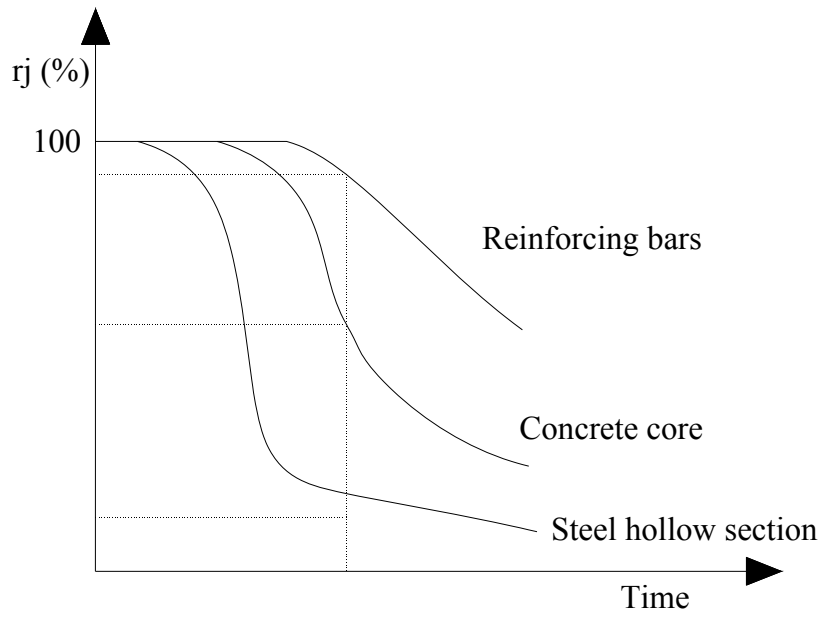

Fig. (9). Evolution of the strength of the different components of a CFT when subjected to fire [70].

\section{IMPACT LOADING}

The general problem of impact is considerably complex. Impact loading involves several aspects related to nonlinearity such as large displacements, material non-linearity, instability, post-buckling strength, friction and material behavior under high strain rates. The physics of impact involves conservation of energy and momentum. In design, the requirement is to provide proof that the structure remains substantially intact, even though damaged. A certain tolerance of Local plastic deformation is permitted, provided the overall response is nearly elastic. The dynamic response of a rigid-perfectly-plastic clamped beam under transverse impact loading has been examined extensively [83]. In addition, it is well understood that steel is a strain-rate sensitive material, and for such materials it is well known that the plastic flow stress increases with strain rate. Circular and rectangular hollow sections (CHS and RHS respectively) have been analyzed profusely $[84,85]$ in particular with applications related to the oil and energy industries [86] (due to the usage of pipelines and offshore engineering). Research concerning the vulnerability assessment of concrete columns subjected to impact loading is also available [87]. Research dealing with CFT in construction is, however, less abundant in last decades. Impact loading may be due to traffic and in construction, is generally assumed as transversal to the members. For the sake of accounting for this type of loading, structural codes provide guidance for calculating equivalent static forces on a structure in an impact event.

The vast majority of studies concerning CFT under impact loading are experimental. Several experimental techniques are employed for measuring key characteristics concerning impact loading. One of the most popular tests is called Drop Hammer Rig, consisting of a controlled weight that impacts the specimen to be tested whose potential energy is precisely known in advance. Other techniques such as gas guns and the split Hopkinson bar are also used. The former corresponds to a light-gas gun in which the piston is powered by a chemical reaction. The working fluid is usually helium or hydrogen. As the pressure builds up to the desired level, the disk tears open, allowing the high-pressured gas to pass into the barrel. The maximum amount of energy available when the projectile begins moving is ensured. The latter technique is based upon stress propagation within a bar (wave-based). The specimen is placed between of two bars (the incident and the transmitted bars, respectively). At the end of the former, a stress wave is created (thus propagating through the bar toward the specimen). This wave is deemed as being the incident wave. Once reaching the specimen, the wave splits into two smaller ones. Among these generated waves, the transmitted wave, travels through the specimen and into the transmitted bar, causing plastic strain in the specimen. The other wave (namely, the reflected wave), is literally reflected away from the specimen and travels back down the incident bar.

As far as known by the author, studies dealing with impact loading in CFT aimed at buildings and construction started during last decade [88]. Shan et al. provided test results on CFT subjected to impact loading by using a gas gun. The main objective was to apply axial impact on CFST stub columns. Results showed that the axial strength of CFST specimens increases under impact load.

Active research concerning impact loading in CFT has been performed by Xiao et al. [89]. These researchers performed tests on CFST stub columns but in this case, with a split Hopkinson pressure bar. Simplified computation methods for the axial strength of the member were derived from the obtained test results. Sequentially, Xiao and Shen [90] performed research concerning the axial impact behavior of CFST columns with drop hammer tests. The main objective was to determine the influence of impact energy. One comprehensive methodology for deriving analytical formulae from experimentally obtained results was presented in [91, 
92] with emphasis in noncircular CFT. Other recent works concerning square CFT subjected to impact loading include experiments and analytical solutions [93]. On the other hand, additional testing in circular CFT was performed in [94] as well as in [95], in which a summary of hitherto performed tests worldwide is presented comprehensively in tables.

Moreover, a new generation of numerical simulations concerning CFT is starting [96, 97]. As numerical methods become more robust and the computing capacity is no longer an issue, the high nonlinearity involved in the impact loading phenomena (buckling, crushing, high strain rate, dynamic effects etc) may be studied in a more detailed and accurate fashion.

\section{CONCLUSION AND FUTURE RESEARCH TRENDS}

In this paper, an up-to-date review of the earlier work related to the structural behavior of concrete-filled circular steel tubes (CFT) is presented. The main focus of this review is to include recent research related to accidental loading namely, seismic events, fire or impact loading. These studies are of the utmost importance for researchers dealing with the structural vulnerability of structures assembled with CFT. In addition, the review includes up-to-date references concerning the static behavior of these members.

The review includes a vast amount of references in an attempt to condense the research works that has nowadays been used in structural codes as well as new methods. It is worth pointing out that several universities deploy continuously updating websites/wikis in which tests, references and major studies concerning CFT are collected. It is worth pointing out that among the three main topics depicted throughout the paper, impact loading has been studied to a lesser extent.

Research concerning coupled phenomena such as impact at high temperatures [98], impact loading in CFT with new materials $[99,100]$ or bonding after fire conditions of CFT $[101,102]$ open new trends that may contribute to the field and consequently, may provide greater insight concerning the depicted phenomena. Numerical methods dealing with impact, high strain rate and particularly high nonlinearity may be developed to a greater extent and thus, further insight on this topic may provide a more accurate assessment of the structural vulnerability of CFT. Advanced applications and further developments of CFT are a continuous source of research [103].

\section{CONFLICT OF INTEREST}

The authors confirm that this article content has no conflict of interest.

\section{ACKNOWLEDGEMENTS}

Declared none.

\section{REFERENCES}

[1] D. Goode, "Composite columns - 1819 tests on concrete-filled steel tube columns compared with Eurocode 4", The Structural Engineer, vol. 86, no. 16, 2008.
[2] “Columns Database”. The Association for Steel-Concrete Composite Structures (ASCCS). Bradford Centre for Sustainable Environments. University of Bradford. http://www. bradford.ac.uk/research/rkt-centres/centre-for-sustainable-environ ments/associationforsteel-concretecompositestructures/columnsdata base/ Retrieved in September 2014

[3] M. Shams, and M. Saadeghvaziri, "State of the art of concretefilled steel tubular columns," ACI Journal, vol. 94, no. 5, pp. 558571, 1998.

[4] B. Gourley, C. Tort, M. Denavit, P. Schiller, and J. Hajjar, " $A$ Synopsis of Studies of the Monotonic and Cyclic Behavior of ConcreteFilled Steel Tube Members, Connections, and Frames," NSEL Report Series. NSEL-008. Department of Civil and Environmental Engineering University of Illinois at Urbana-Champaign, 2008

[5] M. Romero, J. Bonet, and S. Ivorra, "Review of Nonlinear Analysis Models for Concrete-Filled Tubular (CFT) columns," In: Proceedings in Innovation in Civil and Structural Engineering Computing, Rome, Italy, Saxe-Coburg Publications, 2002.

[6] F. Richart, A. Brandzaeg, and R. Brown, A study of the failure of concrete under combined compressive stresses University of Illinois Bulletin, Bulletin 185. Champaign (IL, USA): University of Illinois Engineering Experimental Station, 1928.

[7] N. Gardner, and E. Jacobson, "Structural behavior of concretefilled steel tubes," ACI Journal, vol. 64, no. 7, pp. 404-412, 1967.

[8] G. Hatzigeorgiou, "Numerical model for the behaviour and capacity of circular CFT columns," Part I: Theory, Engineering Structures, vol. 30, no. 6, pp. 1573-1578, 2008.

[9] K. Susantha, H. Ge and T. Usami, "A capacity prediction procedure for concrete-filled steel columns," Journal of Earthquake Engineering, vol. 5, no. 4, pp. 483-520, 2001.

[10] M. Johansson, "The efficiency of passive confinement in CFT columns", Steel and Composite Structures, vol. 2, no. 5, pp. 379396, 2002.

[11] M. Johansson, and K. Gylltoft, "Mechanical behavior of circular steel-concrete composite stub columns," Journal of Structural Engineering, vol. 128, no. 8, pp. 1073-1081, 2002.

[12] EN1994. Eurocode 4, "Design of composite steel and concrete structures Part 1.1", General rules and rules for buildings, CEN, 2004

[13] R. Chacón, E. Mirambell, and E. Real, "Capacidad resistente de pilas metálicas tubulares rellenas de hormigón (CFT) en puentes integrales," Informes de la Construcción, vol. 64, no. 527, pp. 355370, 2012.

[14] W. de Oliveira, S. Nardin, A. El Debs, and M. El Debs, "Influence of concrete strength and length/diameter on the axial capacity of CFT columns," Journal of Constructional Steel Research, vol. 65, no. 12 , pp. 2103-2110, 2009.

[15] A. Beck, W. de Oliveira, S. Nardim, and A. El Debs, "Reliabilitybased evaluation of design code provisions for circular concretefilled steel columns," Engineering Structures, vol. 31, no. 10, pp. 2299-2308, 2009.

[16] A. Kuranovas, D. Goode, A. Kvedaras, and S. Zhong, "Load bearing capacity of concrete-filled composite columns," Journal of Civil Engineering and Management, vol. 15, pp. 21-33, 2009.

[17] M. Elchalakani, X. Zhao, and R. Grzebieta. "Concrete-filled circular steel tubes subjected to pure bending," Journal of Constructional Steel Research, vol. 57, no. 11, pp. 1141-1168, 2001.

[18] B. Evirgen, A. Tuncan, and K. Taskin, "Structural behavior of concrete filled steel tubular sections (CFT/CFSt) under axial compression,” Thin-Walled Structures, vol. 80, no. 7, pp. 46-56, 2014.

[19] Z. Lu, and Y. Zhao, "Suggested empirical models for the axial capacity of circular CFT stub columns," Journal of Constructional Steel Research, vol. 66, no. 6, pp. 850-862, 2010.

[20] A. Wheeler, and R. Bridge, "The behavior of circular concretefilled thin-walled steel tubes in flexure," In: ASCE, Proceedings of Composite construction in steel and concrete V, pp. 412-423, 2006

[21] Y. Deng, C. Tuan, Q. Zhou, and Y. Xiao, "Flexural strength analysis of non-post-tensioned and post-tensioned concrete-filled circular steel tubes", Journal of Constructional Steel Research, vol. 67, no. 2, pp. 192-202, 2011.

[22] J. Moon, C. Roeder, D. Lehman, and H. Lee, "Analytical modeling of bending of circular concrete-filled steel tubes," Engineering Structures, vol. 42, no. 9, pp 349-361, 2012. 
[23] M. Chitadawi, and M. Narasimhan, "Behavior of eccentrically loaded concrete-filled steel tubular columns," Journal of Constructional Steel Research, vol. 65, no. 8-9, pp. 1836-1845, 2009.

[24] H. Hu, C. Huang, and Z. Chen, "Finite element analysis of CFT columns subjected to an axial compressive force and bending moment in combination," Journal of Constructional Steel Research, vol. 61, no. 12, pp. 1692-1712, 2005.

[25] T. Fujimoto, A. Mukai, I. Nishiyama, and K. Sakino, " Behavior of eccentrically loaded concrete-filled steel tubular columns," Journal of Structural Engineering, vol. 130. Special Issue: Composite and Hybrid Structures. pp. 203-212, 2004.

[26] P. Neogi, H. Sen, and J. Chapman, "Concrete-filled tubular steel columns under eccentric loading," The Structural Engineer, vol. 47, no. 5, pp. 187-195, 1969.

[27] R. Knowles, and R. Park, "Strength of concrete-filled steel tubular column," Journal of the Structural Division, ASCE, vol. 95, pp. 2565-2587, 1969

[28] J. Hajjar, B. Gourley, C. Tort, M. Denavit, and P. Schiller P, "Steel-Concrete Composite Structural Systems," Department of Civil and Environmental Engineering, Northeastern University, Boston, Massachusetts, <http://www.northeastern.edu/composite systems >. 2013 (retrieved in September 2014)

[29] M. Bradford, H. Loh, and B. Uy, "Slenderness limits for filled circular tubes," Journal of Constructional Steel Research, vol. 58, no. 2, pp. 243-252, 2002.

[30] Q. Liang, and B. Uy, "Theoretical study on the post-local buckling of steel plates in concrete-filled box columns," Computers and Structures, vol. 75, no. 5, pp. 479-490, 2000.

[31] R. Chacón, E. Mirambell, and E. Real, "Local buckling in concretefilled circular tubes (CFT)," In: Proceedings of the $14^{\text {th }}$ International Symposium on Tubular Structures, London, Leroy Gardner, Ed., pp. 35-45, 2012.

[32] Y. Kwon, S. Seo, and D. Kang, "Prediction of the squash loads of concrete-filled tubular section columns with local buckling," ThinWalled Structures, vol. 49, no. 1, pp. 85-93, 2011.

[33] Q. Liang, B. Uy, and R. Liew, "Nonlinear analysis of concretefilled thin-walled steel box columns with local buckling effects," Journal of Constructional Steel Research, vol. 62, no. 6, pp. 581591, 2006.

[34] V. Patel, Q. Liang, and M. Hadi, "Nonlinear analysis of axially loaded circular concrete-filled stainless steel tubular short columns," Journal of Constructional Steel Research, vol. 101, no. 10, pp. 9-18, 2014.

[35] Q. Ren, L. Han, D. Lam, and W. Li, "Tests on elliptical concrete filled steel tubular (CFST) beams and columns," Journal of Constructional Steel Research, vol. 99, no. 8, pp. 149-160, 2014.

[36] A. Varma, J. Ricles, R. Sause, and L. Lu, "Seismic behavior and modeling of high-strength composite concrete-filled steel tube (CFT) beam-columns," Journal of Constructional Steel Research, vol. 58 , no. 5-8, pp. 725-758, 2002.

[37] A. Zubydan, and A. ElSabbagh, "Monotonic and cyclic behavior of concrete-filled steel-tube beam-columns considering local buckling effect," Thin-Walled Structures, vol. 49, no. 4, pp. 465-481, 2011.

[38] X. Mao, and Y. Xiao, "Seismic behavior of confined square CFT columns," Engineering Structures, vol. 28, no. 10, pp. 1378-1386, 2006.

[39] L. Wu, L. Chung, S. Tsai, T. Shen, and G. Huang, "Seismic behavior of bolted beam-to-colums connections for concrete-filled steel tube," Journal of Constructional Steel Research, vol. 61, no. 1, pp. 1387-1410, 2005

[40] I. Sheet, A. Gunasekaran, and G. MacRae, "Experimental investigation of CFT column to steel beam connections under cyclic loading," Journal of Constructional Steel Research, vol. 86, no. 7, pp. 167-182, 2013.

[41] Y. Alostaz, and S Schneider "Analytical behavior of connections to concrete-filled steel tubes," Journal of Constructional Steel Research, vol. 40, no. 2, pp. 95-127, 1996.

[42] J. Chan, J. Chen, and W. Jin. "Experiment investigation of stress concentration factor of concrete-filled tubular T joints," Journal of Constructional Steel Research, vol. 66, no. 12, pp. 1510-1515, 2010.
[43] S. Chiew, S. Lie, and C. Dai, "Moment resistance of steel I-Beam to CFT column connections," Journal of Structural Engineering, vol. 127, no. 10, pp. 1164-1172, 2001.

[44] H. Hu, C. Chen, and M. Huang, "Nonlinear finite element analysis of CFT-to-bracing connections subjected to axial compressive forces," Engineering Structures, vol. 33, no. 5, pp. 1479-1490, 2011.

[45] M. Hassan, H. Ramadan, M. Abdel-Mooty, and S. Mourad, "Behavior of concentrically loaded CFT braces connections," Journal of Advanced Research, vol. 5, no. 2, pp. 243-252. 2014.

[46] M. Saisho, and K. Goto, "Restoring force model of concrete filled steel tube column under seismic load," In: Proceedings of the $9^{\text {th }}$ Pacific Structural Steel Conference, vol. 1, pp. 453-458, 2001.

[47] K. Goto, "Damage limit of concrete eilled steel tube frame under strong ground motion," Proceedings of the $15^{\text {th }}$ World Congress on Earthquake Engineering, WCEE, Lisbon, Portugal, 2012.

[48] M. Saisho, M. Kato, and S. Gao, "Local buckling of CFT-column under seismic load," Proceedings of the $13^{\text {th }}$ World Congress on Earthquake Engineering, Paper 2614, WCEE, Vancouver, Canada, 2004

[49] Y. Goto, G. Kumar, and K. Seki, "Finite element analysis for hysteretic behavior of thin-walled CFT columns with large crosssections," Procedia Engineering, vol. 14, pp. 2021-2030, 2011.

[50] R. Chacón, E. Mirambell, and E. Real, "Strength and ductility of concrete-filled tubular piers of integral bridges," Engineering Structures, vol. 46, no. 1, pp. 234-246, 2013.

[51] G. Grandjean, J. Grimault, and L. Petit, "Détermination de la durée au feu des profiles creus remplis de béton," CIDECT Research Project 15B-80/10. Cologne, Germany, Comité International pour le Développement et l'Etude de la Construction Tubulaire, 1980.

[52] K. Kordina, and W. Klingsch, "Fire resistance of composite columns of concrete filled hollow sections," CIDECT Research Project 15C1/C2-83/27, Cologne, Germany, Comité International pour le Développement et l'Etude de la Construction Tubulaire, 1983.

[53] H. Matsumura, and H. Sakuma, "Experimental study on fire resistance of concrete-filled square tubular steel columns without fireproof coating," In: Proceedings of the $2^{\text {nd }}$ Pacific Structural Steel Conference, Gold Coast, Australia, 1989.

[54] T. Okada, T. Yamaguchi, Y. Sakumoto, and K. Keira, "Loaded heat tests of full-scale columns of concrete-filled tubular steel structure using fire-resistant steel for buildings," In: Proceedings of the $3^{\text {rd }}$ International Conference on Steel-Concrete Composite Structures, Association for International Cooperation and Research in Steel-Concrete Composite Structures, Fukuoka, Japan, September 26-29, pp. 101-106, 1991.

[55] M. Chabot, and T. Lie, "Experimental Studies on the Fire Resistance of Hollow Steel Columns Filled with Bar-Reinforced Concrete," IRC Internal Report No. 268, National Research Council of Canada, Institute for Research in Construction, Ottawa, Canada. 1992.

[56] T. Lie, and M. Chabot. "Experimental Studies on the Fire Resistance of Hollow Steel Columns Filled with Plain Concrete," IRC Internal Report No. 611, National Research Council of Canada, Ottawa, Ontario, Canada 1992.

[57] T. Lie, and M. Chabot, "A method to predict the fire resistance of circular concrete filled hollow steel columns," Journal of Fire Protection Engineering, vol. 2, no. 4, pp. 111-126, 1991.

[58] T. Lie, and D. Stringer, "Calculation of the fire resistance of steel hollow structural section columns filled with plain concrete," $\mathrm{Ca}$ nadian Journal of Civil Engineering, vol. 21, no. 3, pp. 382-385, 1994.

[59] Y. Sakumoto, T. Okada, M. Yoshida, and S. Tasaka, "Fire resistance of concrete-filled, fire-resistant steel tube columns," Journal of Materials in Civil Engineering, vol. 6, no. 2, pp. 169-184, 1994.

[60] V. Kodur, and T. Lie, "Performance of concrete-filled steel columns exposed to fire," Journal of Fire Protection Engineering, vol. 7, no. 2, pp. 1-9, 1996.

[61] V. Kodur, "Design equations for evaluating fire resistance of SFRC-filled HSS columns," Journal of Structural Engineering, vol. 124, no. 6, pp. 671-677, 1998 .

[62] V. Kodur, "Performance-based fire resistance design of concretefilled steel columns," Journal of Constructional Steel Research, vol. 51, no. 6, pp. 21-36, 1999. 
[63] L. Han, "New developments in fire resistance of concrete filled steel tubes in China," In: Proceedings of the International Conference, Innsbruck, Austria, September 16-18, 1997, International Association of Bridge and Structural Engineers, Lausanne, Switzerland, pp. 391-396, 1997.

[64] L. Han, "Fire performance of concrete filled steel tubular beamcolumns," Journal of Constructional Steel Research, vol. 57, no. 6, pp. 695-709, 2001.

[65] L. Han, H. Yang, and S. Cheng, "Residual strength of concrete filled RHS stub columns after exposure to high temperatures," $A d$ vances in Structural Engineering, vol. 5, no. 2, pp. 123-134, 2002.

[66] L. Han, X. Zhao, Y. Yang, and J. Feng, "Experimental study and calculation of fire resistance of concrete-filled hollow steel columns," Journal of Structural Engineering, vol. 129, no. 3, pp. 346356, 2003.

[67] L. Han, and J. Huo, "Concrete-filled hollow structural steel columns after exposure to ISO-834 fire standard," Journal of Structural Engineering, vol. 129, no. 1, pp. 68-78, 2003.

[68] EN1993-1-3. Eurocode 3: "Design of steel structures. part 1-2. general rules-structural fire design", Brussels, Belgium, 2005

[69] D. Rush, L. Bisby, A. Melandinos, and B. Lane B, "Fire resistance design of unprotected concrete filled steel hollow sections: metaanalysis of available furnace test data," Fire Safety Science, vol. 10, pp. 1549-1562, 2011.

[70] A. Espinós, M. Romero, and A. Hospitaler, "Simple calculation model for evaluating the fire resistance of unreinforced concrete filled tubular columns," Engineering Structures, vol. 42, pp. 231244, 2012.

[71] Y. Wang, "A simple method for calculating the fire resistance of concrete-filled CHS columns," Journal of Constructional Steel Research, vol. 54, no. 3, pp. 365-386, 2000.

[72] Y. Wang, and A. Orton, "Fire resistant design of concrete filled tubular steel columns," The Structural Engineer, vol. 86, no. 19, pp. 40-45, 2008.

[73] Y. Wang, "Some considerations in the design of unprotected concrete-filled steel tubular columns under fire conditions," Journal of Constructional Steel Research, vol. 44, no. 3, pp. 203-223, 1998.

[74] J. Aribert, C. Renaud, and B. Zhao, "Simplified fire design for composite hollow-section columns," In: Proceedings of the Institution of Civil Engineers, Structures \& Buildings, vol. 16, pp. 325336,2008

[75] J. Ribeiro, R. Fakury, and E. de las Casas, "Eurocode structural fire design and its application for composite circular hollow section columns," Journal of the Brazilian Society of Mechanical Science and Engineering, vol. 30, no. 1, pp. 39-46, 2008.

[76] L. Twilt, R. Hass, W. Klingsch, M. Edwards, and D. Dutta, Design Guide for Structural Hollow Section Columns Exposed to Fire, The Steel Construction Institute: Berkshire, U.K., 1994.

[77] A. Espinos, A. Hospitaler, and M. Romero, "Fire resistance of axially loaded slender concrete filled steel tubular columns: development of a three-dimensional numerical model and comparison with Eurocode 4," Acta Polytechnica, vol. 49, no. 1, pp. 39-43, 2009.

[78] A. Espinos, M. Romero, and A. Hospitaler, "Advanced model for predicting the fire response of concrete filled tubular columns," Journal of Constructional Steel Research, vol. 66, no. 8-9, pp. 1030-1046, 2010.

[79] J. Ding, and Y. Wang. "Realistic modelling of thermal and structural behaviour of unprotected concrete filled tubular columns in fire," Journal of Constructional Steel Research, vol. 64, no. 10, pp. 1086-1102, 2008.

[80] M. Romero, V. Moliner, A. Espinos, C. Ibañez, and A. Hospitaler, "Fire behavior of axially loaded slender high strength concretefilled tubular columns," Journal of Constructional Steel Research, vol. 67 , no. 12, pp. 1953-1965, 2011.

[81] Z. Tao, L. Han, B. Uy, and X. Chen, "Post-fire bond between the steel tube and concrete in concrete-filled steel tubular columns," Journal of Constructional Steel Research, vol. 67, no. 3, pp. 484496, 2011.

[82] N. Tondini, V. Hoang, J. Demonceau and J. Franssen, "Experimental and numerical investigation of high-strength steel circular columns subjected to fire". Journal of Constructional Steel Research, vol. 80, no. 10, pp. 57-81. 2013.
[83] J. Liu, and N. Jones, "Dynamic response and failure of a rigid plastic clamped beam struck by a mass at any point on the span," International Journal of Solids and Structures, vol. 24, no. 3, pp. 251-270, 1988.

[84] M. Zeinoddini, G. Parke, and J. Harding, "Axially pre-loaded steel tubes subjected to lateral impacts: an experimental study," International Journal of Impact Engineering, vol. 27, no. 6, pp. 669-690, 2002.

[85] M. Zeinoddini, J. Harding, and G. Parke, "Axially pre-loaded steel tubes subjected to lateral impacts (a numerical simulation)," International Journal of Impact Engineering, vol. 35, no. 11, pp. 12671269, 2008.

[86] M. Zeinoddini, J. Harding, and G. Parke, "Effect on impact damage on the capacity of tubular members of offshore structures," Marine Structures, vol. 11, no. 4-5, pp. 141-158, 1998.

[87] H. Thilakarathna, D. Thambiratnam, M. Dhanasekar, and N. Perera, "Numerical simulation of axially loaded concrete columns under transverse impact and vulnerability assessment," International Journal of Impact Engineering, vol. 37, no. 11, pp. 1100-1112, 2010.

[88] J. Shan, R. Chen, W. Zhang, Y. Xiao, W. Yi, and F. Lu, "Behavior of concrete filled tubes and confined concrete filled tubes under high speed impact," Advances in Structural Engineering, vol. 10, no. 2, pp. 209-218, 2007.

[89] Y. Xiao, J. Shan, Q. Zheng, B. Chen, and Y. Shen, "Experimental studies on concrete filled steel tubes under high strain rate loading," Journal of Materials in Civil Engineering, vol. 21, no. 10, pp. 569-577, 2009.

[90] Y. Xiao, and Y. Shen, "Impact behaviors of CFT and CFRP confined CFT stub columns," Journal of Composite Construction, vol. 16, no. 6, pp. 662-670, 2012.

[91] M. Bambach, H. Jama, X. Zhao, and R. Grzebieta, "Hollow and concrete filled steel hollow sections under transverse impact loads," Engineering Structures, vol. 30, no. 10, pp. 2859-2870, 2008.

[92] M. Bambach, "Design of hollow and concrete filled steel and stainless steel tubular columns for transverse impact loads," ThinWalled Structures, vol. 49, no. 10, pp. 1251-1260, 2011.

[93] A. Remennikov, S. Kong, and B. Uy, "Response of foam and concrete-filled square steel tubes under low-velocity impact loading". Journal of Performance of Constructed Facilities, vol. 25, no. 5, pp. 373-381, 2011.

[94] Y. Deng, C. Tuan, and Y. Xiao, "Flexural behavior of concretefilled circular steel tubes under high-strain rate impact loading," Journal of Structural Engineering, vol. 138, no. 3, pp. 449-459, 2012.

[95] L. Han, C. Hou, X. Zhao, and K. Rasmussen, "Behaviour of highstrength concrete filled steel tubes under transverse impact loading," Journal of Constructional Steel Research, vol. 92, no. 1, pp. 25-39, 2014.

[96] M. Yousuf, B. Uy, Z. Tao, A. Remennikov, and J. Liew, “Transverse impact resistance of hollow and concrete filled stainless steel columns," Journal of Constructional Steel Research, vol. 82, no. 1, pp. 177-189, 2013.

[97] R. Wang, L. Han, and C. Hou, "Behaviour of concrete filled steel tubular (CFST) members under lateral impact: experiment and FEA model," Journal of Constructional Steel Research, vol. 80, no. 10, pp. 188-201, 2013.

[98] J. Huo, Y. He, and B. Chen, "Experimental study on impact behaviour of concrete-filled steel tubes at elevated temperatures up to $800{ }^{\circ} \mathrm{C}$," Materials and Structures, vol. 47, pp. 263-283, 2014.

[99] M. Yousuf, B. Uy, Z. Tao, A. Remennikov, and R. Liew, "Impact behaviour of pre-compressed hollow and concrete filled mild and stainless steel columns," Journal of Constructional Steel Research, vol. 96 , no. 5, pp. 54-68, 2014.

[100] M. Yousuf, B. Uy, Z. Tao, A. Remennikov, and R. Liew, "Transverse impact resistance of hollow and concrete filled stainless steel columns," Journal of Constructional Steel Research, vol. 82, no. 3, pp. 177-189, 2013.

[101] Z. Tao, L. Han, B. Uy, and X. Chen, "Post-fire bond between the steel tube and concrete in concrete-filled steel tubular columns," Journal of Constructional Steel Research, vol. 67, no. 3, pp. 484496, 2011. 
[102] M. Fidelis, B. Uy, Z. Tao, and Z. Wang, "Post-fire bond between the steel tube and concrete in concrete-filled steel tubular columns," Journal of Constructional Steel Research, vol. 95, no. 4, pp. 141-161, 2014.
[103] L. H. Han, and R. Bjorhovde, "Developments and advanced applications of concrete-filled steel tubular (CFST) structures: Members. Journal of Constructional Steel Research, vol. 100, no. 9, pp. 211228, 2014.

Received: October 14, 2014

Revised: October 20,2014

Accepted: November 28, 2014

(C) Rolando Chacón; Licensee Bentham Open.

This is an open access article licensed under the terms of the Creative Commons Attribution Non-Commercial License (http://creativecommons.org/licenses/ by-nc/3.0/) which permits unrestricted, non-commercial use, distribution and reproduction in any medium, provided the work is properly cited. 